Article

\title{
Predicting Loneliness from Where and What People Do
}

\author{
Kristi J. MacDonald ${ }^{1, *}$, Gonneke Willemsen ${ }^{2}$, Dorret I. Boomsma ${ }^{2} \mathbb{D}$ and \\ Julie Aitken Schermer $3, *$ (iD \\ 1 Department of Psychology, The University of Western Ontario, 1151 Richmond St., London, \\ ON N6A 5C2, Canada \\ 2 Netherlands Twin Register, Department of Biological Psychology, Vrije Universiteit Amsterdam, \\ Van der Boechorststraat 7-9, 1081 BT Amsterdam, The Netherlands; a.h.m.willemsen@vu.nl (G.W.); \\ di.boomsma@vu.nl (D.I.B.) \\ 3 Management and Organizational Studies, The University of Western Ontario, 1151 Richmond St., London, \\ ON N6A 5C2, Canada \\ * Correspondence: kmacd252@uwo.ca (K.J.M.); jharris@uwo.ca (J.A.S.); \\ Tel.: +1-519-661-2111 (ext. 84699) (J.A.S.)
}

Received: 12 March 2020; Accepted: 9 April 2020; Published: 14 April 2020

check for updates

\begin{abstract}
The many devastating mental health outcomes associated with chronic loneliness is the motivation behind research into examining personal and demographic characteristics of the lonely. The present study sought to examine the connection of where people live (degree of urbanization) and what people do (leisure activities) with self-report of loneliness in a large sample $(N=8356)$ of unrelated Dutch adults. Information regarding where people live and what they do in their leisure time was entered into a regression analysis for self-reported loneliness. The overall regression was significant and accounted for $2.8 \%$ of the loneliness scale scores. Significant independent predictors for loneliness were living in heavily urbanized areas and engaging in fewer social activities. People who went sightseeing or to amusement parks/zoos or who participated in clubs reported being less lonely. Spending time using a computer predicted higher self-report loneliness scores. Consistent with previous research, after controlling for other variables, gender was not a significant predictor of loneliness but both a younger age and a curvilinear or U-shaped curve of age predicted loneliness (the younger and the much older). The results suggest that meaningful interpersonal interactions may result in lower feelings of loneliness.
\end{abstract}

Keywords: lonely; adult; gender; age; urbanization; leisure

\section{Introduction}

In 2018, the United Kingdom made international headlines by announcing a Minister of Loneliness to address growing concerns about negative outcomes for its lonely citizens. Such outcomes include increased anxiety, depression, and suicidal ideation (Chang et al. 2017; Conde-Sala et al. 2019; Maes et al. 2019). Physical health is also at risk; loneliness is associated with poor cardiac health, inadequate sleep patterns, and lower subjective health ratings (Cacioppo et al. 2002; Peltzer and Pengpid 2017). To be lonely is to feel distress and dissatisfaction with one's current social relationships (Perlman and Peplau 1981). These feelings can be adaptive, making one more attuned to emotional expression in others or motivating one to seek social interactions and develop relationships (Lucas et al. 2010; Luhmann et al. 2015). But, when these attempts fail, and social relationships are absent or deficient, loneliness becomes chronic, and the mental and physical health consequences emerge. Evidence of these consequences has prompted research into the characteristics 
of lonely people. The purpose of the present analysis was to extend the literature on the factors in human life that are associated with loneliness. Of particular interest for this paper are where people live and what they choose to do in their leisure time.

Leisure time is when work, school, or family responsibilities do not restrict the individual; time when people can choose to do something they enjoy. Engaging in leisure activities has been associated with identity development and mental well-being (Lampinen et al. 2006; Layland et al. 2018). Activities that require perseverance or that contribute to career development have a positive impact on personal growth and happiness, and active and productive leisure activities have been found to predict involvement in social relationships (Kim et al. 2015; Toepoel 2013). On the other hand, tasks that are sedentary (Vancampfort et al. 2019), done alone (Queen et al. 2014), or perceived as meaningless (Tam and Chan 2019) are associated with greater loneliness. Leisure activity is most often by personal choice, making it a particularly revealing variable for individual differences.

Urban centers often provide many options for leisure activities, including entertainment, organized sports, or community gatherings; however, there is evidence that despite these opportunities, the geographical location can influence loneliness and mental health concerns. Wen et al. (2006) found that factors such as crowding and air pollution contributed negatively to self-rated health, even beyond the social characteristics of the community. Studies investigating loneliness and urbanization have typically focused on older adults, and the results do suggest that loneliness increases when these individuals are further from urban centers (Finlay and Kobayashi 2018). Burholt and Scharf (2014) reported that the loneliness in rurally located older adults only increased when their location caused the limitation of access to social activities and access to family and friends. Without the factor of age, comparing urban and rural communities, mood and anxiety disorders are more prevalent in urban centers and residents report lower social supports, whereas rural inhabitants report a stronger sense of community and lower rates of depression (Karmakar and Raychaudhuri 2015; Peen et al. 2010; Romans et al. 2011). This finding is supported by one study that examined a general and clinical population in India, where individuals in urban environments were lonelier than those living rurally (Karmakar and Raychaudhuri 2015). There is considerable interest in loneliness and urbanization, with news outlets and statistics agencies reporting numbers of individuals who live alone, but very few reviewed studies use specific measures of loneliness or seek to gain the perspective of a broad range of the adult population.

Utilizing a large sample of adults ranging from late adolescence to over 90 years, variables such as where people live (the degree of urbanization) and what activities people do in their leisure time were examined as potential predictors of loneliness in addition to the commonly used predictors of gender and age. In particular, it was expected that solitary leisure activities, such as computer use, may be associated with higher self-report loneliness scores, possibly because of the lack of rich, or face-to-face, interpersonal interactions with others. In contrast, participating in activities, which include social interactions, and living in smaller, less urban, communities are expected to predict lower loneliness scores. This combination of variables have not been analyzed together in the literature and have potential for insight into the lifestyle of the lonely.

\section{Method}

\subsection{Participants}

Participants were 8356 adult individuals (3802 men, 4552 women, and 2 transgender) with a mean age of 45.57 years $(S D=14.89$, range 17 to 97$)$. For this sample, men $(M=49.94, S D=13.63)$ were slightly but significantly older than the women $(M=42.26, S D=14.72 ; t=23.79, p<0.001)$. To generate this sample, an individual was randomly selected from each family in the Netherlands Twin Register. The ANTR has collected longitudinal data every two to three years since the late 1980s and has recruited twins through birth registration and city council information (see Boomsma et al. 2006; van Beek et al. 2014; Willemsen et al. 2013). In addition to twins themselves, the ANTR includes parents, siblings, 
spouses, and adult offspring. The subset of data for the present analysis was from the 2004 survey and this combination of variables and sample has not been presented or published prior to this study.

\subsection{Measures}

In addition to the demographic information of age and sex, the postal code of the participants at the time of survey completion was used to obtain information on the degree of urbanization according to information provided by Statistics Netherlands (Centraal Bureau voor de Statistiek [CBS] 2006). The urbanization level was based on the mean number of addresses per square kilometer within a circle of one kilometer of the postal code region and coded on a scale of 1 (non-urban, $<500$ addresses) to 5 (very heavy; >2500 addresses; see Willemsen et al. 2005).

Self-report loneliness was assessed by three items from the revised UCLA Loneliness Scale (Russell et al. 1980). Items asked how often an individual felt that they lacked companionship, how often the individual felt that they were "left out", and how often the individual felt that they were "isolated from others". Responses to these items were on a 1 "Hardly ever", 2 "Sometimes", to 3 "Often" scale. The internal consistency (coefficient alpha) for these three items was 0.76 in the present data. A total loneliness score represents the aggregate of the three items.

Participants also provided responses to four general leisure time activities and five specific activities, as outlined in Table 1. The general leisure activities were rated on a 1 "Hardly ever" to 6 "Several times a week" scale. Specific activities required a response on a 1 "Hardly ever" to 4 "More than 10 hours a week" scale.

Table 1. Descriptive statistics of the leisure activities.

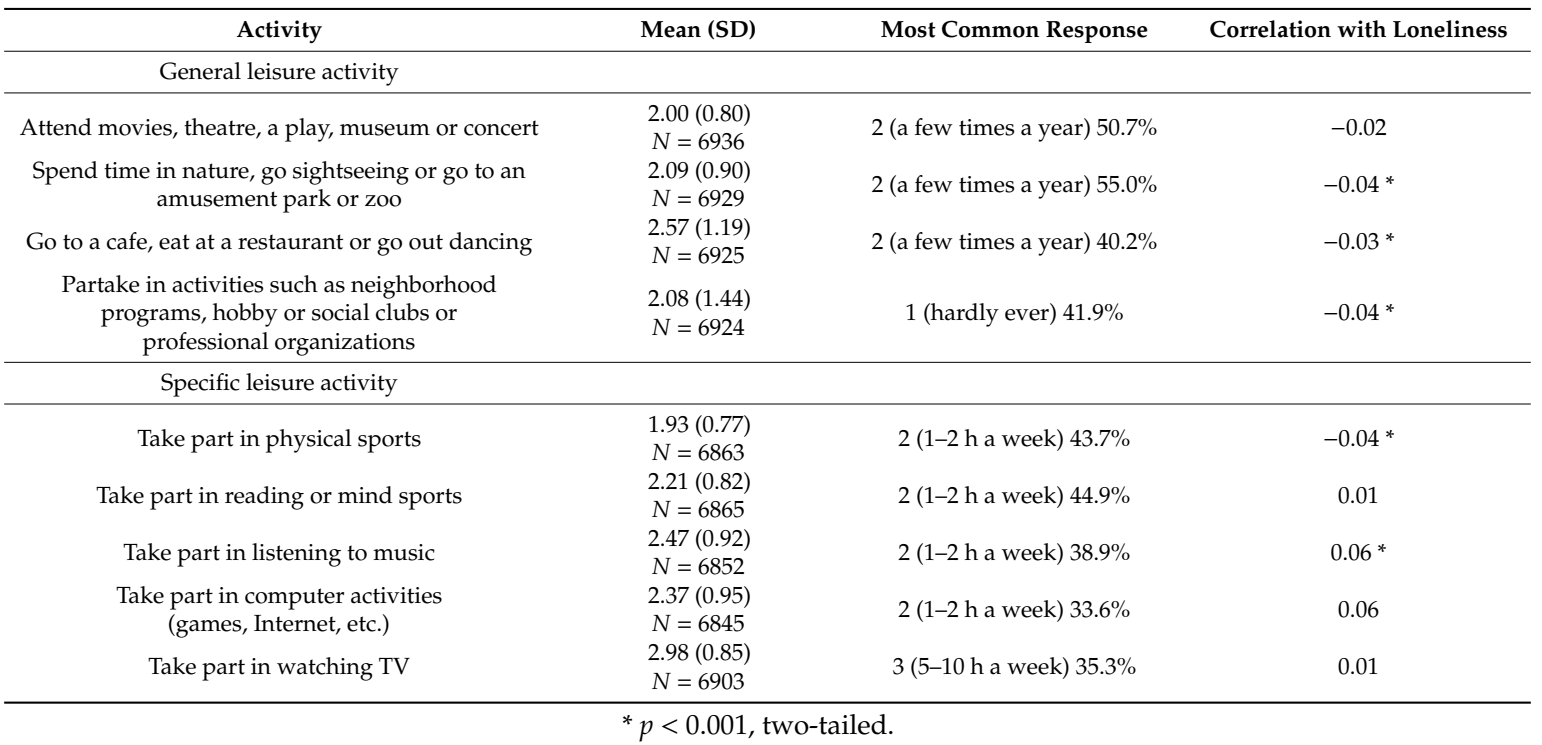

\section{Results}

For all of the analyses reported below, list-wise deletion was used when participants had missing items; therefore, sample sizes are specified for each analysis. Individual endorsement rates of loneliness were positively skewed (3.8\% or fewer of the sample responded "often" to the three items) with the majority of the sample $(63.9 \%$ to $81.7 \%)$ provided the "hardly ever" response to each item, creating a slight skew in overall loneliness $(N=7854)$. To examine the effects of urbanization, a one-way ANOVA was conducted comparing the five urbanization categories (very heavy $N=578$, heavy $N=1218$, moderately $N=1052$, low $N=1302$, and not urbanized $N=1347$ ). The overall $F$-statistic was significant $(F(4,5507)=3.41, p<0.01)$ due to the significant mean difference between the very heavy urbanization group $(M=3.89, S D=1.25)$ and the not urban group $(M=3.72, S D=1.08$; Tukey HSD = 0.17, $p<0.05$; see Figure 1 for means plot). 


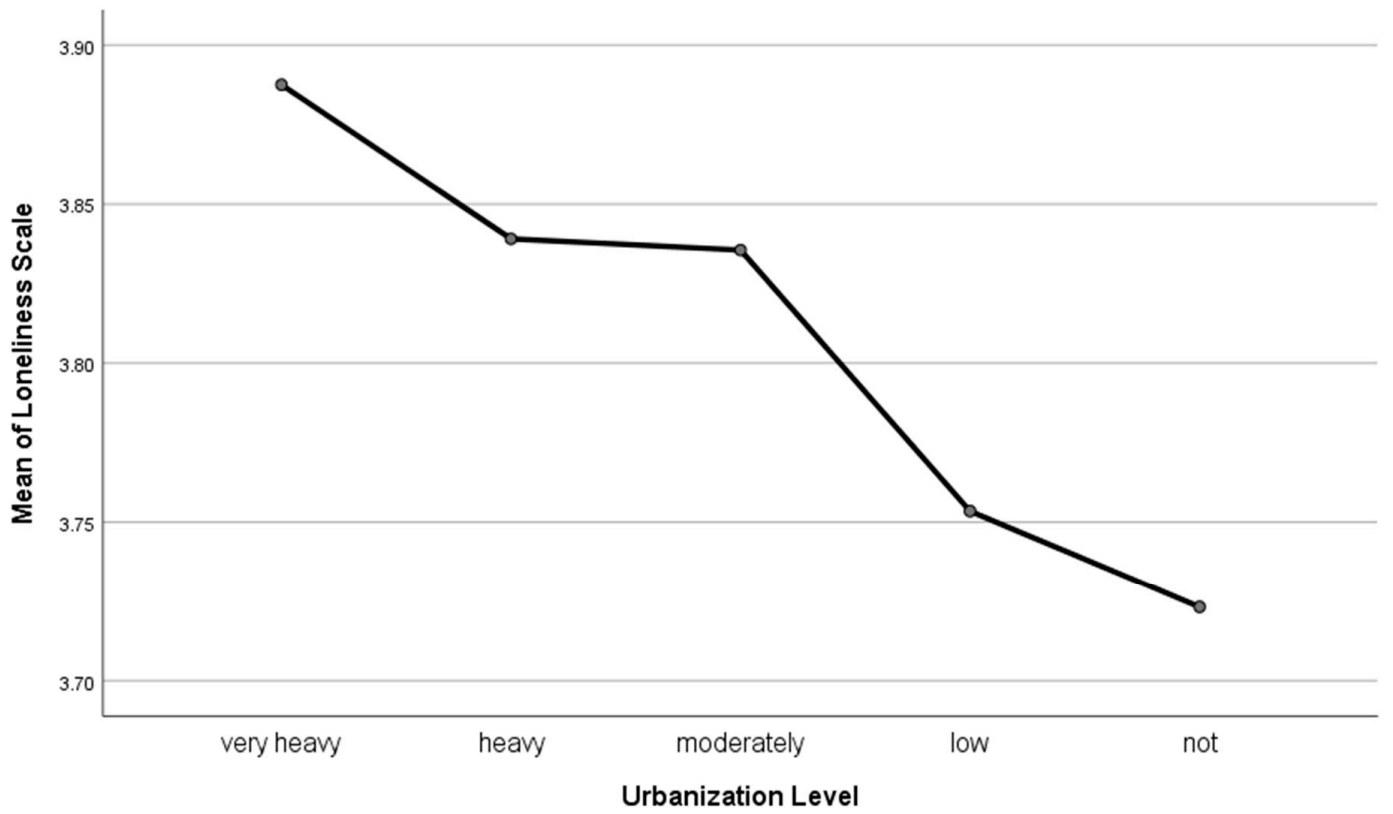

Figure 1. Means plot of lonely scale scores by urbanization levels.

Descriptive statistics for the four general leisure time activities and five specific activities are provided in Table 1. Except for the activity of taking part in "neighborhood programs, hobby or social clubs or professional organizations", the majority of participants reported engaging in the activity a few times a year for the first four items and at least $1-5 \mathrm{~h}$ a week for the five specific activities ("Take part in ..." ).

\section{Predicting Loneliness}

The relationships among the predictor variables were analyzed using Kendall's Tau-B (Khamis 2008). Age had small negative Tau-B values $(\leq-0.21)$ with attending movies/theatre, eating out, physical sports, listening to music, and computer activities. Age had small positive $(\leq 0.17)$ Tau-B association values with the other activity variables. Age also had a small negative Tau-B $(\leq-0.04)$ with urbanization levels. Urbanization (higher scores indicate less urbanization) had small negative Tau-B values $(\leq-0.10)$ with attending movies/theatre, spending time in nature/zoo, eating out, reading, listening to music, and computer activities, suggesting that urban individuals engaged in these activities slightly more than rural individuals. Small positive Tau-B values $(\leq 0.09)$ were found between urbanization and the remaining variables suggesting that, for example, rural individuals were more likely to participate in social clubs. Within the activities themselves, all had positive Tau-B values with the exception of watching television, which had small negative values $(\leq-0.07)$ with attending movies/theatre, spending time in nature/zoo, eating out, partaking in social clubs, and physical sports.

Age, sex, and urbanization were entered into a regression equation with the activity variables to try to predict loneliness scores. The overall regression was significant $(F(12,4562)=10.77, p<0.001)$ and accounted for $2.8 \%$ of the loneliness scale scores (Adjusted $R^{2}=0.025$ ). The standardized beta weights are listed in Table 2. Although not large, the beta weights do present an interesting set of results. Younger people were lonelier overall, and the relationship between age and loneliness fit a convex curvilinear pattern such that younger and older people were more likely to have higher self-report loneliness scores, which is consistent with previous research (e.g., Victor and Yang 2012). Both sex and the interaction of sex and age were non-significant predictors. People who spent more time in nature (such as going sightseeing, to an amusement park or zoo) or were involved in neighborhood programs, clubs, or organizations had significantly lower loneliness scores. In contrast, spending time engaging in computer activities positively predicted loneliness scores. 
Table 2. Regression results of predicting loneliness scores.

\begin{tabular}{lcc}
\hline \multicolumn{1}{c}{ Predictor } & Standardized Beta & $t$ \\
\hline Age & -0.44 & $-4.37^{* *}$ \\
Sex $(1=$ male, 2 = female) & 0.02 & 0.28 \\
Age $^{2}$ & 0.35 & $4.34^{* *}$ \\
Age by Sex & 0.13 & 1.78 \\
Urbanization (1 = very heavy, 5 = not urban) & -0.05 & $-3.12^{* *}$ \\
Movies, theatre, a play, museum or concert & -0.02 & -1.47 \\
Nature, sightseeing or amusement park or zoo & -0.04 & $-2.28^{*}$ \\
Go to a cafe, eat at a restaurant or go out dancing & -0.02 & -0.91 \\
Neighborhood programs, hobby or social clubs or & -0.03 & $-2.28^{*}$ \\
professional organizations & -0.02 & -1.01 \\
Physical sports & -0.02 & -1.15 \\
Reading or mind sports & 0.03 & 1.59 \\
Listening to music & 0.04 & $2.55^{*}$ \\
Computer activities (games, Internet, etc.) & -0.01 & -0.63 \\
Watching TV & \\
\hline
\end{tabular}

${ }^{*} p<0.05 ;{ }^{* *} p<0.01$, two-tailed.

\section{Discussion}

In this study, urbanization was divided into five levels, and while the effect of the difference between adjacent levels was fairly small, the difference between the two extremes (very heavy urbanization and not urban) revealed that living in areas that are more rural was associated with lower self-report loneliness scores. In general, rural communities are more likely to contain extended family and have less transience than urban environments, creating a close community; urban environments often provide less integration into society (Jones et al. 1985). With fewer people in proximity, opportunities for a wide social network may be decreased; however, Stokes (1985) found that the density of a social network was more strongly related to loneliness than the overall size. While individuals in an urban environment may meet many people and have a variety of friendships, those friendships are less likely to be connected, contributing to feelings of isolation. In contrast, feeling as though one has a network of friends that are able to support you as a group may decrease loneliness. The Netherlands is a fairly densely populated country, so that even its most remote locations are less than two hundred kilometers from an urban center, but further studies in geographically larger countries reveal a similar pattern. Romans et al. (2011) found greater feelings of social support and community in rural Canada compared to Canadian cities. Likewise, among older adults in Australia, loneliness was less prevalent in rural dwellers (Beere et al. 2019).

On examining leisure activities, taking part in computer activities was positively associated with loneliness; that is, more time spent on the computer was associated with greater loneliness. This finding partially confirms the initial hypothesis that engaging in activities lacking face-to-face social interaction would contribute to loneliness. Other studies have found similar results with computer activities; loneliness is positively associated with computer use and Internet addiction (Toepoel 2013; Zhang et al. 2018); however past studies have not looked at computer use alongside other leisure activities. Among the other specific activities, watching TV and listening to music can be both solitary and social. Reading is the only other activity in this study that almost never involves face-to-face social interaction, yet it does not contribute significantly to loneliness. While many people would say that there were times they "couldn't put the book down", reading has never been a concern for behavioral addiction or as a contributor to psychological distress. There is clearly something different about people's engagement with computers that is associated with loneliness. Nowland et al. (2018) have suggested that a key factor is that greater loneliness is observed when one's online world begins to replace the offline world; loneliness is highly related to substituting face-to-face relationships and interactions for those that are online. Over and above one's participation in other activities, computer use remains a strong predictor of loneliness. Future research seeking to describe computer use in 
more detail and investigate the motivation for online social interactions would be valuable for further understanding the link between leisure-time computer use and loneliness.

Consistent with the present study hypotheses, the results indicated that leisure activities that include being in public or engaging with others (e.g., going to a zoo, attending a play, participating in organizations) are associated with lower loneliness. Lonely people are more likely to experience social anxiety (Jones et al. 1981) and therefore, may avoid public or social leisure activities. Lonely individuals also tend to experience less enjoyment from their experiences, so they may be less motivated to make the effort to overcome anxiety-provoking situations for the sake of a leisure activity (Queen et al. 2014). The results suggest that individuals who choose to spend their time in public or in social activities are less lonely. Moreover, the choice of leisure activity was not a matter of access from the perspective of urbanization (i.e., having more access to social opportunities in an urban location), as the correlations between specific activities and degree of urbanization were very small.

Age was not found to have large correlations with specific leisure activities, though a small trend was found with younger individuals more likely to attend movies/theatre, eat out, play sports, listen to music and go on the computer. Related to loneliness, age followed a U-shaped pattern suggesting greater loneliness in young adulthood, and towards elder adulthood. This is consistent with most previous research (e.g., Joiner and Rudd 1996; Pinquart and Sörensen 2001; Victor and Yang 2012).

\section{Limitations and Future Directions}

The present study was cross-sectional and descriptive, so while rural areas, social activities, and computer activity account for variance in loneliness, causal statements cannot be made. Self-report measures also leave room for some error in estimation, particularly for time estimates on leisure activities. Future studies might consider daily tracking for more specific measurement. While loneliness is a subjective experience and widely measured by self-report, identifying the number of close friends may be a useful measure to help corroborate loneliness, as Hamid and Lok (2000) found significant differences in number of close friendships between lonely and non-lonely individuals. Additionally, the data for the present research was collected in 2004, and the interim history has seen significant changes in technology and its integration into social and daily life. It is admittedly difficult for research to keep up with the rapid development in communicative technology, but nonetheless important to mark changes and evaluate outcomes. Future research in how loneliness is experienced with respect to newer smartphone technology and the expansion of social media would be beneficial. There is certainly research done on the impact of social media on psychological outcomes (e.g., Hunt et al. 2018; Yang 2016) but little taking into account other "offline" leisure activities.

Computers now encompass some of the other leisure activities identified in this study, namely watching television, reading, and listening to music. There is some evidence that social media can enhance relationships and those that are not lonely spend more time on social media than those who are lonely (Nowland et al. 2018; Twenge et al. 2018). Even within social media use studies, the ways that people interact have different relationships with psychological outcomes. For example, Yang (2016) found that interacting and browsing on "Instagram" related to lower loneliness scores, but only posting on "Instagram" was associated with increased loneliness. In smartphone research, both social and non-social use (reading, accessing entertainment, etc.) contribute to habitual and excessive smartphone use, which is associated with depression, anxiety, and loneliness (Casale and Fioravanti 2011; Van Deursen et al. 2015). While the increase of social media and variety of computer use has changed since the data was collected, the trends around excessive computer use continue to point to problematic outcomes in loneliness and other mental health problems. Identifying patterns of use that are healthy and can combat loneliness will be essential for the future.

\section{Conclusions}

The results of this study contribute to the literature on disentangling the lives of those who live with loneliness. As loneliness has been found to be due to both genetic and environmental factors 
(Boomsma et al. 2005; Schermer and Martin 2019), but where people live is due mainly to environmental factors (Willemsen et al. 2005), understanding how loneliness, the home environment, and activities are connected adds to the understanding of loneliness. The knowledge is important, as knowing factors associated with loneliness across adulthood can not only inform individual treatments and recommendations, but also draw attention to the wider fields of community development in urban centers and access to social opportunities.

Author Contributions: Conceptualization, J.A.S.; Methodology, J.A.S.; software, J.A.S.; validation, J.A.S.; formal analysis, J.A.S.; writing—original draft preparation, K.J.M.; investigation, D.I.B., G.W.; resources, D.I.B.; data curation, G.W.; writing - review and editing, K.J.M., J.A.S., D.I.B. and G.W.; supervision, J.A.S. and D.I.B.; project administration, G.W.; funding acquisition, D.I.B. All authors have read and agreed to the published version of the manuscript.

Funding: Data collection and genotyping in NTR were supported by the Netherlands Organization for Scientific Research (904-61-090, 85-10-002,904-61-193,480-04-004, 400-05-717, Spi56-464-14192 and 480-15-001/674); and the National Institutes of Health (NIH, R37 AG033590-08) to J. Cacioppo.

Acknowledgments: We thank all volunteer participants who contributed data to this study. DIB acknowledges the Royal Netherlands Academy of Science Professor Award (PAH/6635).

Conflicts of Interest: The authors declare no conflict of interest.

\section{References}

Beere, Paul, Sally Keeling, and Hamish Jamieson. 2019. Ageing, loneliness, and the geographic distribution of New Zealand's interRAI-HC cohort. Social Science \& Medicine 227: 84-92.

Boomsma, Dorret I., Gonneke Willemsen, Conor V. Dolan, Louise C. Hawkley, and John T. Cacioppo. 2005. Genetic and environmental contributions to loneliness in adults: The Netherlands Twin Register study. Behavior Genetics 35: 745-52. [CrossRef] [PubMed]

Boomsma, Dorret I., Eco J. C. de Geus, Jacqueline M. Vink, Janine H. Stubbe, Marjin A. Distel, Jouke-Jan Hottenga, Danielle Posthuma, Toos C. E. M. van Beijesterveldt, James J. Hudziak, Meike Bartels, and et al. 2006. Netherlands twin register: From twins to twin families. Twin Research and Human Genetics 9: 849-57. [CrossRef] [PubMed]

Burholt, Vanessa, and Thomas Scharf. 2014. Poor Health and Loneliness in Later Life: The Role of Depressive Symptoms, Social Resources, and Rural Environments. Journals of Gerontology, Series B: Psychological Sciences and Social Sciences 69: 311-24. [CrossRef] [PubMed]

Cacioppo, John T., Louise C. Hawkley, L. Elizabeth Crawford, John M. Ernst, Mary H. Burleson, Ray B. Kowalewski, William B. Malarkey, Eve Van Cauter, and Gary G. Berntson. 2002. Loneliness and health: Potential mechanisms. Psychosomatic Medicine 64: 407-17. [CrossRef] [PubMed]

Casale, Silvia, and Giulia Fioravanti. 2011. Psychosocial correlates of internet use among Italian students. International Journal of Psychology 46: 288-98. [CrossRef]

Centraal Bureau voor de Statistiek (CBS). 2006. Kerncijfers postcodegebieden 2004. Available online: https: //www.cbs.nl/nl-nl/publicatie/2006/08/kerncijfers-postcodegebieden-2004 (accessed on 24 February 2006).

Chang, Qingsong, Chee Hon Chan, and Paul S. F. Yip. 2017. A meta-analytic review on social relationships and suicidal ideation among older adults. Social Science \& Medicine 191: 65-76.

Conde-Sala, Josep L., Josep Garre-Olmo, Laia Calvó-Perxas, Oriol Turró-Garriga, and Joan Vilalta-Franch. 2019. Course of depressive symptoms and associated factors in people aged 65+ in Europe: A two-year follow-up. Journal of Affective Disorders 245: 440-50. [CrossRef]

Finlay, Jessica M., and Lindsay C. Kobayashi. 2018. Social isolation and loneliness in later life: A parallel convergent mixed-methods case study of older adults and their residential contexts in the Minneapolis metropolitan area, USA. Social Science E Medicine 208: 25-33.

Hamid, P. Nicholas, and David P. P. Lok. 2000. Loneliness in Chinese adolescents: A comparison of social support and interpersonal trust in 13 to 19 year olds. International Journal of Adolescence and Youth 8: 45-63. [CrossRef]

Hunt, Melissa G., Rachel Marx, Courtney Lipson, and Jordyn Young. 2018. No more FOMO: Limiting social media decreases loneliness and depression. Journal of Social and Clinical Psychology 37: 751-68. [CrossRef]

Joiner, Thomas E., Jr., and M. David Rudd. 1996. Disentangling the interrelations between hopelessness, loneliness, and suicidal ideation. Suicide and Life-Threatening Behavior 26: 19-26. [PubMed] 
Jones, Warren H., J. E. Freemon, and Ruth Ann Goswick. 1981. The persistence of loneliness: Self and other determinants. Journal of Personality 49: 27-48. [CrossRef]

Jones, Dee A., Christina R. Victor, and Norman J. Vetter. 1985. The problem of loneliness in the elderly in the community: Characteristics of those who are lonely and the factors related to loneliness. Journal of the Royal College of General Practitioners 35: 136-39. [PubMed]

Karmakar, Asmita, and Souvik Raychaudhuri. 2015. Loneliness \& Depression: An Urban Syndrome? International Journal of Indian Psycholog 2: 174-82.

Khamis, Harry. 2008. Measures of association. How to choose? Journal of Diagnostic Medical Sonography 24: 155-62. [CrossRef]

Kim, Junhyoung, Jinmoo Heo, In Heok Lee, and Jun Kim. 2015. Predicting personal growth and happiness by using serious leisure model. Social Indicators Research 122: 147-57. [CrossRef]

Lampinen, P., R. L. Heikkinen, M. Kauppinen, and E. Heikkinen. 2006. Activity as a predictor of mental well-being among older adults. Aging and Mental Health 10: 454-66. [CrossRef]

Layland, Eric K., Brian J. Hill, and Larry J. Nelson. 2018. Freedom to explore the self: How emerging adults use leisure to develop identity. Journal of Positive Psychology 13: 78-91. [CrossRef]

Lucas, Gale M., Megan L. Knowles, Wendi L. Gardner, Daniel C. Molden, and Valerie E. Jefferis. 2010. Increasing social engagement among lonely individuals: The role of acceptance cues and promotion motivations. Personality and Social Psychology Bulletin 36: 1346-59. [CrossRef]

Luhmann, Maike, Felix D. Schönbrodt, Louise C. Hawkley, and John T. Cacioppo. 2015. Loneliness and social behaviours in a virtual social environment. Cognition and Emotion 29: 548-58. [CrossRef]

Maes, Marlies, Stefanie A. Nelemans, Sofie Danneel, Belén Fernández-Castilla, Wim Van den Noortgate, Luc Goossens, and Janne Vanhalst. 2019. Loneliness and social anxiety across childhood and adolescence: Multilevel meta-analyses of cross-sectional and longitudinal associations. Developmental Psychology 55: 1548. [CrossRef] [PubMed]

Nowland, Rebecca, Elizabeth A. Necka, and John T. Cacioppo. 2018. Loneliness and social internet use: Pathways to reconnection in a digital world? Perspectives on Psychological Science 13: 70-87. [CrossRef] [PubMed]

Peen, Jaap, Robert A. Schoevers, A. T. Beekman, and Jack Dekker. 2010. The current status of urban-rural differences in psychiatric disorders. Acta Psychiatrica Scandinavica 121: 84-93. [CrossRef] [PubMed]

Peltzer, Karl, and Supa Pengpid. 2017. Loneliness: Its correlates and associations with health risk behaviours among university students in 25 countries. Journal of Psychology in Africa 27: 247-55. [CrossRef]

Perlman, Daniel, and Letitia A. Peplau. 1981. Toward a Social Psychology of Loneliness. In Personal Relationships in Disorder. Edited by Steve Duck and Robin Gilmour. London: Academic Press, pp. 31-56. [CrossRef]

Pinquart, Martin, and Silvia Sörensen. 2001. Influences on loneliness in older adults: A meta-analysis. Basic and Applied Social Psychology 23: 245-66. [CrossRef]

Queen, Tara L., Robert S. Stawski, Lindsay H. Ryan, and Jacqui Smith. 2014. Loneliness in a day: Activity engagement, time alone, and experienced emotions. Psychology and Aging 29: 297-305. [CrossRef]

Romans, Sarah, Marsha Cohen, and Tonia Forte. 2011. Rates of depression and anxiety in urban and rural Canada. Social Psychiatry and Psychiatric Epidemiology 46: 567-75. [CrossRef]

Russell, Dan, Letitia. A. Peplau, and Carolyn E. Cutrona. 1980. The revised UCLA loneliness scale: Concurrent and discriminant validity evidence. Journal of Personality and Social Psychology 39: 472-80. [CrossRef]

Schermer, Julie A., and Nicholas G. Martin. 2019. A behavior genetic analysis of personality and loneliness. Journal of Research in Personality 78: 133-37. [CrossRef]

Stokes, Joseph P. 1985. The relation of social network and individual difference variables to loneliness. Journal of Personality and Social Psychology 48: 981-90. [CrossRef]

Tam, Katy Y. Y., and Christian S. Chan. 2019. The effects of lack of meaning on trait and state loneliness: Correlational and experience-sampling evidence. Personality and Individual Differences 141: 76-80. [CrossRef]

Toepoel, Vera. 2013. Ageing, leisure, and social connectedness: How could leisure help reduce social isolation of older people? Social Indicators Research 113: 355-72. [CrossRef] [PubMed]

Twenge, Jean M., Gabrielle N. Martin, and W. Keith Campbell. 2018. Decreases in psychological well-being among American adolescents after 2012 and links to screen time during the rise of smartphone technology. Emotion 18: 765-80. [CrossRef] [PubMed] 
van Beek, Jenny H. D. A., Marleen H. M. de Moor, Lot M. Geels, Gonneke Willemsen, and Dorret I. Boomsma. 2014. Explaining individual differences in alcohol intake in adults: Evidence for genetic and cultural transmission? Journal of Studies on Alcohol and Drugs 75: 201-10. [CrossRef]

Van Deursen, Alexander J. A. M., Colin L. Bolle, Sabrina M. Hegner, and Piet A. M. Kommers. 2015. Modeling habitual and addictive smartphone behavior: The role of smartphone usage types, emotional intelligence, social stress, self-regulation, age, and gender. Computers in Human Behavior 45: 411-20. [CrossRef]

Vancampfort, Davy, Garcia Ashdown-Franks, Lee Smith, Joseph Firth, Tine Van Damme, Lore Christiaansen, Brendon Stubbs, and Ai Koyanagi. 2019. Leisure-time sedentary behavior and loneliness among 148,045 adolescents aged 12-15 years from 52 low- and middle-income countries. Journal of Affective Disorders 251: 149-55. [CrossRef]

Victor, Christina R., and Keming Yang. 2012. The prevalence of loneliness among adults: A case study of the United Kingdom. Journal of Psychology: Interdisciplinary and Applied 146: 85-104. [CrossRef]

Wen, Ming, Louise C. Hawkley, and John T. Cacioppo. 2006. Objective and perceived neighborhood environment, individual SES and psychosocial factors, and self-rated health: An analysis of older adults in Cook County, Illinois. Social Science E Medicine 63: 2575-90.

Willemsen, Gonneke, Danielle Posthuma, and Dorret I. Boomsma. 2005. Environmental factors determine where the Dutch live: Results from the Netherlands Twin Register. Twin Research and Human Genetics 8: 312-17. [CrossRef]

Willemsen, Gonneke, Jacqueline M. Vink, Abdel Abdellaoui, Anouk den Braber, Jenny H. D. A. Van Beek, Harmen H. M. Draisma, Jenny van Dongen, Dennis van't Ent, Lot M. Geels, Rene van Lien, and et al. 2013. The Adult Netherlands Twin Register: Twenty-five years of survey and biological data collection. Twin Research and Human Genetics 16: 271-81. [CrossRef]

Yang, Chia-chen. 2016. Instagram use, loneliness, and social comparison orientation: Interact and browse on social media, but don't compare. Cyberpsychology, Behavior, and Social Networking 19: 703-8. [CrossRef] [PubMed]

Zhang, Shujie, Yu Tian, Yi Sui, Denghau Zhang, Jieru Shi, Peng Wang, Weixuan Meng, and Yingdong Si. 2018. Relationships between social support, loneliness, and internet addiction in Chinese postsecondary students: A longitudinal cross-lagged analysis. Frontiers in Psychology 9: 1707. [CrossRef] [PubMed]

(C) 2020 by the authors. Licensee MDPI, Basel, Switzerland. This article is an open access article distributed under the terms and conditions of the Creative Commons Attribution (CC BY) license (http://creativecommons.org/licenses/by/4.0/). 